\title{
The Role of High-sensitivity C-reactive Protein Serum in Assessing Troponin T in Acute Myocardial Infarction
}

\author{
Taufik Indrajaya $^{1 *}$, Mgs Irsan Saleh², Miliyandra Miliyandra ${ }^{1}$ \\ ${ }^{1}$ Department of Internal Medicine, Cardiovascular Division, Faculty of Medicine, Universitas Sriwijaya, Indonesia; ${ }^{2}$ Department \\ of Pharmacology, Faculty of Medicine, Universitas Sriwijaya, Indonesia
}

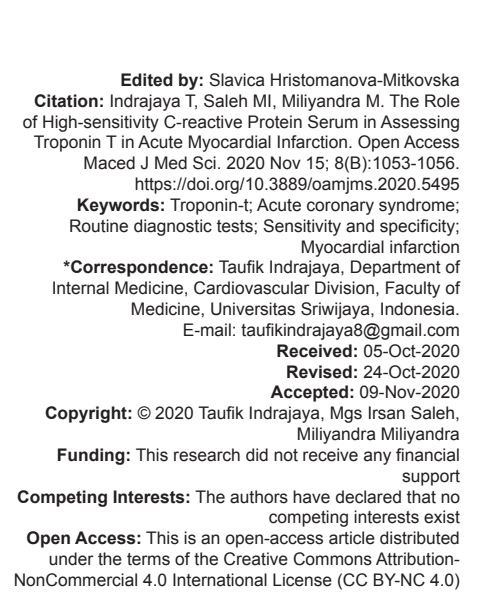

\section{Abstract}

BACKGROUND: The incidence of acute myocardial infarction (AMI) is increasing worldwide. Inflammation plays an essential role in the initiation and progression of atherosclerosis and the pathogenesis of acute cardiovascular events. C-reactive protein (CRP) has been shown to have prognostic value in patients with acute coronary syndrome but the most promising use of CRP has been used for primary use.

AIM: This study was aimed to explore the sensitivity of high-sensitivity CRP (hs-CRP) in assessing troponin T in AMI.

METHODS: The study design was an observational study to assess the sensitivity and specificity of hsCRP against troponin T in patients with AMI with ST-elevation and without ST-elevation. This research was conducted in Palembang, Indonesia. The study subjects were 56 patients with an acute myocardial infusion that met the inclusion and exclusion criteria.

RESULTS: The sensitivity of hs-CRP to troponin-T is $93.7 \%$. The specificity of hs-CRP to troponin T was $37.5 \%$. The positive suspected value is 0.9 , the estimated negative value is 0.5 , the positive likelihood ratio is 1.49 , and the negative likelihood ratio is 0.16

CONCLUSION: hs-CRP is quite sensitive in assessing troponin-T but not specific enough in assessing troponin-T activity.

\section{Introduction}

Acute myocardial infarction (AMI) or better known as coronary heart disease (CHD) is a condition of heart muscle cell death caused by a sudden blockage in the coronary arteries that cause the decreasing blood supply to muscles. Blockages will be followed by thrombosis, vasoconstriction, inflammatory reactions, and distal microemboli. AMI can cause sudden death in sufferers. CHD is the number one cause of death in Europe and America as well as in Indonesia, both for men and women. The morbidity and mortality rate of $\mathrm{CHD}$ in Indonesia has increased sharply in the past 20 years, as seen in the Indonesian Family Health Survey. The survey in 1996 showed that the cause of the disease increased from year to year as a cause of death. In 1975, deaths from heart disease were only $5.9 \%$, in 1981, it increased to $9.1 \%$, in 1986 , it jumped to $16 \%$, and in 1995 , it increased to $19 \%$. The 2001 national census causing death due to cardiovascular disease, including CHD, was $26.4 \%$. In $2013, \pm 478,000$ patients in Indonesia were diagnosed with $\mathrm{CHD}$ at this time, the prevalence of ST-elevation myocardial infarction (STEMI) increased from $25 \%$ to $40 \%$ of all presentations incidence of myocardial infarction [1-5].

In recent years, the incidence of $\mathrm{AMI}$ is increasing worldwide in developing countries. Inflammation plays an essential role in the initiation and progression of atherosclerosis and the pathogenesis of acute cardiovascular events. Inflammation also plays a role in the development of atherosclerosis and CHD. The most common cause is that $\mathrm{CHD}$ is atherosclerosis with erosion or plaque rupture, which causes a transient blockage, partially or totally from arteries. Several risk factors are considered for atherosclerosis which is a significant cause of AMI such as obesity, diabetes, stress, smoking, hypertension, hyperlipidemia, and chronic inflammation due to infection [6]. Troponin-T is the gold standard method for the detection of AMI. A prolonged increase after AMI obscures the increase in $\mathrm{AMI}$ and return infarction besides troponin also has limitations in terms of the price of troponin- $T$ examination, the ability to survive reagents, and support the examination material in the hospital $[1,2]$.

The efforts to look for markers of CHD began in the $19^{\text {th }}$ century. More than $60 \%$ of patients who experience coronary heart problems have only one 
without traditional risk factors and more than half of patients who have average or slightly increased lipid levels. One of the biomarkers that have been owned estimated as an indicator of the inflammatory process in cardiovascular disorders is C-reactive protein (CRP). CRP has been shown to have prognostic value in patients with the acute coronary syndrome, but the most promising use of CRP has been used for primary use. CRP can not only be a marker of critical grade systemic inflammation but can also be directly involved in atherosclerosis [7-11]. In addition to CRP as an inflammatory factor, some studies show serum uric acid levels produced as a determining factor for coronary artery disease and congestive heart failure [12]. Conventional CRP measurements are only adequate for monitoring severe inflammatory conditions but cannot measure accurately for cardiovascular risk protection. Therefore, a more sensitive CRP measurement method is needed to measure CRP increase at lower levels. Routine serum CRP examination (immunonephelometry method) cannot measure CRP levels of more than $3 \mathrm{mg} / \mathrm{L}$. These values are average according to conventional tests, although several studies have shown that at CRP $<3 \mathrm{mg} / \mathrm{L}$ and are a predisposition for atherothrombosis [13]. A high-sensitivity test for CRP is called high-sensitivity CRP (hs-CRP) as an examination to obtain CRP findings that are so small that it is more sensitive to the measurement range between 0.1 and $20 \mathrm{mg} / \mathrm{L}$ [14]. According to this fact, this research was aimed to explore the sensitivity of hs-CRP in AMI.

\section{Methods}

The study design was a diagnostic test to assess the sensitivity and specificity of hs-CRP against troponin $\mathrm{T}$ in patients with $\mathrm{AMI}$ with ST-elevation and without ST-elevation. This research was conducted at Dr. Moh Hoesin General Hospital, Palembang, Indonesia. The study subjects were 56 patients with an AMI that met the inclusion and exclusion criteria. Inclusion criteria were all patients with AMI (STEMI and NSTEMI) who were confirmed based on WHO criteria, namely, typical chest pain complaints, electrocardiography (ECG) examination, and troponin T elevations and were willing to participate in the study by signing informed consent. Exclusion criteria were patients with comorbid diseases such as chronic infection, degenerative disorders, malignancies, and autoimmune disorders.

Myocardial infarction with ST or STEMI elevation is all patients when they arrive or are treated to meet $\mathrm{WHO}$ criteria where two out of three symptoms for chest pain complaints, ECG examination by researchers obtained a description of ST-segment elevation in two consecutive leads and $\geq 0.25 \mathrm{mV}$ in men in under 40 years, $\geq 0.2 \mathrm{mV}$ in men over 40 years, or $\geq 0.15 \mathrm{mV}$ in women and an increase in cardiac enzymes. Myocardial infarction without ST or NSTEMI elevation is all patients when they arrive or are treated in compliance with the WHO criteria which were 2 of 3 criteria for complaints of chest pain, ECG examination by researchers obtained depiction of ST-segment depression $\geq 1 \mathrm{~mm}$, changes in $T \geq 2 \mathrm{~mm}$ waves, and $Q$ waves persistence accompanied by an increase in cardiac enzymes [8,9].

Serum hsCRP levels are taken from blood samples of patients with AMI. If hs-CRP level $<1.0 \mathrm{mg} / \mathrm{L}$, it means low risk of cardiovascular disease, hs-CRP 1.0-3.0 mg/L: Moderate risk of cardiovascular disease (intermediate risk) and hs-CRP $>3.0 \mathrm{mg} / \mathrm{L}(<10 \mathrm{mg} / \mathrm{L}$ ): High risk of cardiovascular disease. High levels of troponin- $T$ are serum troponin- $T$ levels taken from blood samples of patients with AMI. Troponin-T levels are low when $\leq 100 \mathrm{ng} / \mathrm{L}$ and troponin-T levels are high when $>100 \mathrm{ng} / \mathrm{L}[10]$.

All data obtained from this study were analyzed using the SPSS version 22.0 for windows program with a 95\% confidence limit. Descriptive data analysis of categorical variables is presented in numbers and proportions. Descriptive data analysis of numerical variables with normal distribution is presented in the form of mean \pm standard deviation, analysis of numerical descriptive data with abnormal distribution in the form of the median (minimum value-maximum value). Assessing data with normal distribution or abnormal distribution can be descriptive with variance or analytical coefficient with ShapiroWilk. Analysis of normally distributed data using unpaired t-test, whereas if the data are not generally distributed with Mann-Whitney U test. Statistical tests to prove the diagnostic value of uric acid and serum CRP for diagnosing AMI include several quantities such as sensitivity, specificity, positive suspected value, negative predictive value, positive likelihood ratio, and negative likelihood ratio.

\section{Results}

Table 1 of the 56 study subjects found the highest frequency in men as many as 42 subjects (75\%). The age of the patients in this study varied with an average age of $58.68 \pm 9.16$ years. The educational background of the subjects of this study ranging from the most to the lowest in a row was senior high school as many as 39 subjects (69.6\%). The types of jobs were obtained by 12 civil servants $(21.4 \%)$.

Table 2 is a cross-tabulation between hs-CRP and troponin-T levels. Based on Table 2, it is found that the sensitivity of hs-CRP to Troponin $\mathrm{T}$ is $93.7 \%$. The specificity of hs-CRP to troponin-T was $37.5 \%$. The positive suspected value is 0.9 , the estimated negative 
Table 1: Baseline characteristics

\begin{tabular}{ll}
\hline Variable & Description $(\mathrm{n}=56)$ \\
\hline Gender (\%) & \\
$\quad$ Male & $42(75)$ \\
Female & $14(25)$ \\
Age & $58.68 \pm 9.16$ \\
Education (\%) & \\
$\quad$ Primary school & $5(8.9)$ \\
$\quad$ High school & $39(69.6)$ \\
$\quad$ Bachelor degree & $12(21.4)$ \\
Education (\%) & $12(21.4)$ \\
$\quad$ Civil servant & $44(78.5)$ \\
$\quad$ Non-civil servant & Categorical variables are presented in $n(\%)$, numerical variables are normally distributed in the mean +
\end{tabular}

standard deviations, numerical variables are not normally distributed in the median (minimum-maximum)

value is 0.5 , the positive likelihood ratio is 1.49 , and the negative likelihood ratio is 0.16 .

Table 2: hs-CRP versus troponin-T diagnostic test

\begin{tabular}{lllll}
\hline Variable & \multicolumn{2}{l}{ Troponin-T level } & Total \\
\cline { 2 - 3 } & $>100 \mathrm{ng} / \mathrm{l}$ & $\leq 100 \mathrm{ng} / \mathrm{l}$ & \\
\hline hs-CRP level & $\geq 3 \mathrm{mg} / \mathrm{dl}$ & 45 & 5 & 50 \\
& $<3 \mathrm{mg} / \mathrm{dl}$ & 3 & 3 & 6 \\
Amount & 48 & 8 & 56 \\
\hline hs-CRP levels of CRP $\geq 3 \mathrm{mg} / \mathrm{dL}$ is high risk, $<3 \mathrm{mg} / \mathrm{dL}$ is intermediate and low risk; troponin-t $>100 \mathrm{ng} / \mathrm{L}$ is \\
high; $\leq 100 \mathrm{ng} / \mathrm{L}$ is low. hs-CRP: High-sensitivity C-reactive protein
\end{tabular}

high; $\leq 100 \mathrm{ng} / \mathrm{L}$ is low. hs-CRP: High-sensitivity C-reactive protein

\section{Discussion}

Increased troponin-T occurs due to damage to the heart muscle myocyte cells. Troponin will increase in blood after $3 \mathrm{~h}$ after infarction and last for 14 days. Troponin-T has a higher sensitivity and specificity than the creatine kinase-myocardial band [15,16]. In STEMI, a broader atherosclerotic plaque rupture will be followed by an acute thrombosis in the blood vessel lumen, potentially causing total occlusion of the coronary artery lumen, or infarct-related description of ST-elevation segment characterizes larger arteries on the ECG examination of the patient. In contrast, in NSTEMI, the rupture or plaque tear is smaller so that it only causes occultation difficulties. Following the ischemic cascade, the occurrence of an acute process of thrombosis when a decrease will follow total and absence of collateral in myocardial diastolic function followed by a decrease in systolic myocardial function, abnormalities of myocardial movement (wall motion abnormality) will be seen on imaging tests both echocardiography or nuclear examination or MRI. Then, the process of ischemia continues before an ECG abnormality will be seen in the form of ST-elevation followed by complaints of chest pain in patients with AMI [17-19]. If this process continues and no immediate revascularization will result in more extensive myocardial necrosis indicated by high plasma troponin levels [20].

hs-CRP is a marker of systemic inflammation that is quite sensitive to serum. In the condition of AMI, there is a blockage in the coronary arteries. This causes the condition ischemia of heart muscle cells that are plagued by coronary arteries that are blocked. Ischemia will cause hypoxia in the tissues and cells of various organs [20]. Hypoxia causes activation of multiple death receptors and inflammatory receptors to cause mitochondrial dysfunction. This condition causes the death of heart cells which lead to damage and rupture of myocardial cells. Continuation of this condition causes the rupture of myocardial muscle and troponin- $T$ protein. This causes an increase in the activity of the inflammatory marker protein and hs-CRP $[18,20]$. This study shows that hs-CRP is sensitive enough to assess an increase in troponin- $T$ but not specific enough to assess an increase in troponin-T. This is possible because the inflammatory process can take place at various locations, not only in the heart during the process of AMI. The limitation of this study is the small number of samples so that, in future studies, a larger number of participants is needed so that the results obtained will be more representative and reliable.

\section{Conclusion}

hs-CRP is quite sensitive in assessing troponin-T, but it is not specific enough in assessing troponin-T activity.

\section{References}

1. Steg G, James SK, Atar D, Badano LP, Lundqvist CB, Borger MA, et al. ESC guidelines for the management of acute myocardial infarction in patients presenting with ST-segment elevation. Eur Heart J. 2012;33(20):2569-619.

PMid:22922416

2. Thygesen K, Alpert JS, White HD, Jaffe AS, Apple FS, Galvani M, et al. Universal definition of myocardial infarction. Eur Heart J. 2007;28(20):2525-38. https://doi.org/10.1136/hrt.2008.151233 PMid:17951287

3. Crea F, Liuzzo G. Pathogenesis of acute coronary syndromes. J Am Coll Cardiol. 2013;61(1):1-11.

4. Hundekari IA, Pursnani P, Dongre NN. Serum high sensitivity C-reactive protein, creatine kinase-MB, lipid profile and uric acid levels in acute myocardial infarction. $\mathrm{J}$ Chem Pharm Res. 2015;7(2):30-5.

5. Rhee JW, Sabatine MS. Acute coronary syndrome. In: Lilly S, editor. Pathophysiology of Heart Disease. $5^{\text {th }}$ ed. Philadelphia, PA: Lippincott Williams and Wilkins; 2011. p. 58-65.

6. Reddy K, Khaliq A. Recent advances in the diagnosis and treatment of acute myocardial infarction. World $\mathrm{J}$ Cardiol. 2015;7(5):243-76.

PMid:26015857

7. Bhaskar I, Rao SB. New, simple and cheap alternative to troponin test for diagnosis of acute myocardial infarction. Indian J Exp Biol. 2020;40(5):628-30.

PMid: 12622217

8. Nozari Y, Geraiely B. Correlation between the serum levels of uric acid and HS-CRP with the occurrence of early systolic failure of left ventricle following acute myocardial infarction. Acta Med Iran. 2011;49(8):531-5.

PMid:22009810 
9. Eisenhardt SU, Habersberger J, MurphyA, Chen YC, Woollard KJ, Bassler $\mathrm{N}$, et al. Dissociation of pentameric to monomeric C-reactive protein on activated platelets localizes inflammation to atherosclerotic plaques. Circ Res. 2009;105(2):128-37. https://doi.org/10.1161/circresaha.108.190611

PMid:19520972

10. Ridker PM. Cardiology patient page. C-reactive protein: A simple test to help predict risk of heart attack and stroke. Circulation. 2003;108(12):e81-5. https://doi.org/10.1161/01. cir.0000093381.57779.67

PMid:14504253

11. Fadella AA, Boufaris IA. Uric acid levels in patients with acute myocardial infarction. Life Sci J. 2014;11(6):616-8.

12. Spahić E, Hasić S, Kiseljaković E, Resić H, Kulić M. Positive correlation between uric acid and C-reactive protein serum level in healthy individuals and patients with acute coronary syndrome. Med Glas (Zenica). 2015;12(2):128-32. https://doi. org/10.5455/medarh.2017.71.115-118

PMid:26276649

13. Baruah M, Nath CK, Chaudhury B, Devi R, Ivvala AS. A study of serum uric acid and C-reactive protein in acute myocardial infarction. Int J Basic Med Sci Pharm. 2012;2(1):21-4.

14. Omidvar B, Ayatollahi $F$, Alasti M. The prognostic role of serum uric acid level in patients with acute ST elevation myocardial infarction. J Saudi Heart Assoc. 2012;24(2):73-8. https://doi.org/10.1016/j.jsha.2012.01.005
PMid:23960675

15. Badiger RH, Dinesha V, Hosalli A, Ashwin SP. HS-C-reactive protein as an indicator for prognosis in acute myocardial infarction. J Sci Soc. 2014;41(2):118-21. https://doi. org/10.4103/0974-5009.132859

16. Rathore A, Pareek U, Sharma A. A study of high-sensitivity C-reactive protein and trop-T in patients with coronary artery disease. Int J Res Med Sci. 2016;4(4):1051-5. https://doi. org/10.18203/2320-6012.ijrms20160782

17. Boyle AJ, Jaffe AS. Acute myocardial infarction. In: Crowford MH, editor. Current Diagnosis and Treatment: Cardiology. $3^{\text {rd }}$ ed. San Fransisco: McGraw-Hill Companies Inc.; 2009. p. 51-72.

18. Mendis S, Puska P, Norrving B. Global Atlas on Cardiovascular Disease Prevention and Control. Geneva: World Health Organization; 2011. p. 1-25.

19. Srimahachota $S$, Boonyaratavej $S$, Kanjanavanit R, Sritara $P$ Krittayaphong R, Kunjara-Na-ayudhya R, et al. Thai Registry in Acute Coronary Syndrome (TRACS)--an extension of Thai Acute Coronary Syndrome registry (TACS) group: Lower in-hospital but still high mortality at one-year. J Med Assoc Thai. 2012;95(4):508-18. https://doi.org/10.1016/j.cvdpc.2010.06.001 PMid:22612004

20. Eftekhari H, Bukharovich I, Aziz E, Hong MK. Epidemiology and pathophysiology of acute coronary syndrome. In: Hong MK, Herzog E, editors. Acute Coronary Syndrome. London: Springer; 2008. p. 25-36. https://doi.org/10.1007/978-1-84628-869-2_4 